\title{
Polymerization of $\alpha$-Olefins with a Supported Ziegler-type Catalysts. I. Influence of Various Supports on the Polymerization Rate and the Tacticity of Polypropylene.
}

\author{
Kazuo Soga, ${ }^{*}$ Satoshi Katano, Yoshiyuki Akımoto, \\ and Tsutomu Kagrya \\ Department of Hydrocarbon Chemistry, Faculty of Engineering, \\ Kyoto University, Sakyo-ku, Kyoto, Japan.
}

(Received November 24, 1972)

\begin{abstract}
The influence of the support on both the polymerization rate and the tacticity of polypropylene has been widely investigated by using various supported Ziegler-type catalysts. The supports used were metal chloride hydroxide of $\mathrm{Mn}, \mathrm{Co}, \mathrm{Ni}$, $\mathrm{Ba}, \mathrm{Cd}, \mathrm{Fe}, \mathrm{Mg}$, Sr, etc., magnesium hydroxide, silica gel, and some organic polymers such as poly(ethylene glycol), poly(vinyl sulfonic acid) (K-salt) and sodium polyacrylate.

The supported catalysts were prepared by allowing the supporting compounds to react with titanium tetrachloride $\left(\mathrm{TiCl}_{4}\right)$ in boiling $n$-heptane. Polymerizations were carried out in $n$-heptane at $50^{\circ} \mathrm{C}$ with the use of triethylaluminum as an activator. Although the polymerization rate with carrier-free $\mathrm{TiCl}_{4}$ decreased remarkably with the polymerization time, that with supported $\mathrm{TiCl}_{4}$ remains constant during the course of polymerization over several hours. Magnesium hydroxide and magnesium chloride hydroxide-supported catalysts showed the highest activity among the supports.

As for the tacticity, on the other hand, a sharply peaked relationship with a maximum value near $0.70 \AA$ has been found between the tacticity of the produced polypropylene and the ionic radii of the metals used as supports.

The apparent activation energy of the polymerization with magnesium chloride hydroxide-supported $\mathrm{TiCl}_{4}$ catalyst was estimated to be $5.5 \mathrm{kcal} / \mathrm{mole}$ in the temperature range between $20^{\circ} \mathrm{C}$ and $70^{\circ} \mathrm{C}$. This value is equal to that of carrier-free $\mathrm{TiCl}_{4} \mathrm{catalyst}$ at a lower temperature range.
\end{abstract}

KEY WORDS Ziegler Catalyst / Supported Catalyst / Metal Chloride Hydroxide / Propylene Polymerization / Titanium Tetrachloride / Triethylaluminum / Vanadium Tetrachloride / Molecular Weight / Surface Area / Heat of Absorption / Entropy of Adsorption / Kinetics /

A great number of investigations have been carried out so far on the polymerization of propylene with the use of Ziegler-Natta-type catalysts. However, the polymerization mechanism, including the stereoregulation of the produced polymer, is still quite open to discussion. It seems an important clue for settling the polymerization mechanism might come from investigating the influence of the support on the catalytic nature of the Ziegler-type catalysts. Numerous patents relating to supported Ziegler-

* Present address: Research Laboratory of Resources Utilization, Tokyo Institute of Technology, o-okayama, Meguro-ku, Tokyo, Japan.
Natta-type catalysts have been recently reported ${ }^{1}$, however, the precise role of the support on the catalytic behavior is still quite obscure.

The present authors have, therefore, carried out propylene polymerization by using various supported catalysts to investigate the influence of the support on both the polymerization rate and tacticity of polypropylene.

\section{EXPERIMENTAL}

\section{Preparation of the Catalysts}

All the metal hydroxy chlorides were prepared with the same procedures as described below, 
using $\mathrm{MnCl}_{2} \cdot 4 \mathrm{H}_{2} \mathrm{O}, \mathrm{CoCl}_{2} \cdot 6 \mathrm{H}_{2} \mathrm{O}, \mathrm{NiCl}_{2} \cdot 6 \mathrm{H}_{2} \mathrm{O}$, $\mathrm{BaCl}_{2} \cdot 2 \mathrm{H}_{2} \mathrm{O}, \mathrm{FeCl}_{3} \cdot 6 \mathrm{H}_{2} \mathrm{O}, \mathrm{CrCl}_{3} \cdot 6 \mathrm{H}_{2} \mathrm{O}, \mathrm{AlCl}_{3}$. $6 \mathrm{H}_{2} \mathrm{O}, \mathrm{MgCl}_{2} \cdot 6 \mathrm{H}_{2} \mathrm{O}$ and $\mathrm{SrCl}_{2} \cdot 6 \mathrm{H}_{2} \mathrm{O}$, respectively. A $60-\mathrm{g}$ portion of each reagent was dried under vaccum at $100^{\circ} \mathrm{C}$ for $1 \mathrm{hr}$, at $200^{\circ} \mathrm{C}$ for $4 \mathrm{hr}$ and then at $285^{\circ} \mathrm{C}$ for $2 \mathrm{hr}$. $\quad \mathrm{SiO}_{2}$ was prepared by calcinating a commercial silica gel (100$200 \mathrm{mesh}$ ) at $160^{\circ} \mathrm{C}$ for $6 \mathrm{hr}$ in air. $\mathrm{CrCl}_{3}$ was prepared by drying a commercial anhydrous chromium chloride at $185^{\circ} \mathrm{C}$ for $2.5 \mathrm{hr}$ under vacuum after grinding in a nitrogen atmosphere.

$\mathrm{Mg}\left(\mathrm{C}_{2} \mathrm{H}_{5}\right)_{2}$ was prepared by heating at $70^{\circ} \mathrm{C}$ $\mathrm{C}_{2} \mathrm{H}_{5} \mathrm{MgI}$ which had been synthesized by the usual method and distilling under a reduced pressure. As for $\mathrm{Mg}(\mathrm{OH})_{2}$, a commercial reagent was used without further treatment. Commercial poly(ethylene glycol) (600), poly(vinylsulfonic acid) (K-salt), sodium polyacrylate and polypropylene (100\% isotactic) were dried for $1 \mathrm{hr}$ under vacuum at $25^{\circ} \mathrm{C}$.

All the supported catalysts were prepared with the same procedures as indicated below. A $3-g$ portion of each support was placed in a three-necked $200-\mathrm{m} l$ glass flask equiped with a magnetic stirrer. After the flask was completely flushed with nitrogen, a $25-\mathrm{m} l$ portion of purified $n$-heptane and an $18-\mathrm{m} l$ portion of titanium tetrachloride were added. The mixture was vigorously stirred at $98^{\circ} \mathrm{C}$ for $1.5 \mathrm{hr}$ under a nitrogen atmosphere. After most of the soluble part was syringed out, the precipitate was dried in a vacuum at room temperature overnight.

The surface areas of the supports were measured by the BET method with nitrogen adsorption.

\section{Polymerization Procedures and Analysis of the} Polymer

Laboratory-scale polymerizations were carried out at $50^{\circ} \mathrm{C}$ with the same apparatus and procedures as reported in a previous paper, ${ }^{2}$ i.e., by using a $100-\mathrm{m} l$ portion of $n$-heptane as solvent, a 3-g portion of each supported catalyst and a $10-\mathrm{m} l$ portion of triethylaluminum as an activator. The intrinsic viscosity of polypropylene was measured at $135^{\circ} \mathrm{C}$ in decalin containing $0.1-\%$ phenyl- $\beta$-naphtylamine under a nitrogen atomsphere. Molecular weight was calculated by eq $1 .^{3}$

$$
[\eta]=1.07 \times 10^{-4} \bar{M}_{w}{ }^{0.8}
$$

The tacticity of polypropylene was determined by the method of Luongo ${ }^{4}$ with infrared spectra, referred to $995-$ and $974-\mathrm{cm}^{-1}$ bands obtained with a JASCO model DS-403G spectrometer at room temperature.

\section{Adsorption Measurements of Propylene}

A conventional BET apparatus was used for the adsorption experiments. Each sample (support) was allowed to stand in a vacuum system $\left(10^{-3} \mathrm{mmHg}\right)$ for $2 \mathrm{hr}$ at $150^{\circ} \mathrm{C}$ before the adsorption experiment. The adsorption isothems were measured at $25-40^{\circ} \mathrm{C}$ for each sample. The values of the heats and the entropies of propylene adsorption were calculated from eq 2 and 3.

$$
q(\text { heat of adsorption })=R\left(\frac{\ln P_{1}-\ln P_{2}}{1 / T_{1}-1 / T_{2}}\right)
$$

$\triangle S$ (entropy of adsorption)

$$
=-R \frac{T_{2} \ln P_{2} / P^{0}-T_{1} \ln P_{1} / P^{0}}{T_{1}-T_{2}}
$$

Where $P_{1}$ and $P_{2}$ are equilibrium pressures at absolute temperatures of $T_{1}$ and $T_{2}$, and $R$ and $P^{0}$ are the gas constant and the standard pressure, respectively.

\section{Materials}

Propylene, whose purity was more than $99.5 \%$, was obtained from Takachiho Chemicals, Ltd. Triethyl aluminum was from Stauffer Chem. Co. Ltd., and used as a 10-wt $\%$ solution in $n$ heptane. Polymerization grade $n$-heptane was used after refluxing over potassium metal under a nitrogen atmosphere following distillation. The other reagents (GR-grade) were used without any further purifications.

\section{RESULTS AND DISCUSSIONS}

\section{Reaction Mechanism of the Catalyst Formation}

The following shows the observed material balance between before and after drying treatment for magnesium chloride $\left(\mathrm{MgCl}_{2} \cdot 6 \mathrm{H}_{2} \mathrm{O}\right)$ as compared with the theoretical one assuming the dried material is magnesium chloride hydroxide $(\mathrm{Mg}(\mathrm{OH}) \mathrm{Cl})$.

$$
\begin{aligned}
& \text { Observed; } \frac{\text { dried material }}{\mathrm{MgCl}_{2} 6 \mathrm{H}_{2} \mathrm{O}}=\frac{25.0}{60.0}=0.42 \\
& \text { Theoretical; } \frac{\mathrm{Mg}(\mathrm{OH}) \mathrm{Cl}}{\mathrm{MgCl}_{2} 6 \mathrm{H}_{2} \mathrm{O}}=\frac{76.8}{203.3}=0.38
\end{aligned}
$$


It may be said from this that most of magnesium chloride has been transformed by heating into magnesium chloride hydroxide as shown by the equation.

$\mathrm{MgCl}_{2} \cdot 6 \mathrm{H}_{2} \mathrm{O} \stackrel{\text { heat }}{\longrightarrow} \mathrm{Mg}(\mathrm{OH}) \mathrm{Cl}+5 \mathrm{H}_{2} \mathrm{O}+\mathrm{HCl}$ (4)

On the other hand, the infrared spectrum of the precipitate of the reaction product between the heated material (magnesium chloride hydroxide) and titanium tetrachloride showed a broad absorption at about $900 \mathrm{~cm}^{-1}$. This may indicate the formation of a $\mathrm{Mg}-\mathrm{O}-\mathrm{Ti}$ bond.

Judging from the color, yellowish green, of this precipitate, the valency state of titanium may be regarded to remain as four. Accordingly, the following mechanism is postulated for the catalyst formation.

$$
\mathrm{Mg}(\mathrm{OH}) \mathrm{Cl}+\mathrm{TiCl}_{4} \rightarrow \mathrm{ClMgOTiCl}_{3}(\mathrm{~A})+\mathrm{HCl} \text { (5) }
$$

From the material balance between the magnesium hydroxy chloride reagent and the final product (for example, in the case of No. 1 in Figure $3 ; 25.0 \mathrm{~g} \rightarrow 37.0 \mathrm{~g}$ ), it may be said that reaction 5 proceeds to some extent into the inner part of the magnesium chloride hydroxide. The weight of this final product remained constant even after washing it several times with $n$-heptane, so that unreacted titanium tetrachloride can be considered to be completely removed. Here, the compound A existing near the surface is considered to become the active center in the presence of an activator. A similar mechanism is also plausible for most of the inorganic supported catalysts. As for $\mathrm{SiO}_{2}$, on the other hand, the following reaction may occur between the surface hydroxy groups of $\mathrm{SiO}_{2}$ and titanium tetrachloride as reported by J. Murray. ${ }^{5}$

$\mathrm{Si}(\mathrm{OH})($ surface $)+\mathrm{TiCl}_{4} \rightarrow \mathrm{SiOTiCl}_{3}($ surface $)+\mathrm{HCl}$

Accordingly, the active species may be considered to be chemically very close with one another.

\section{Polymerizations without Titanium Tetrachloride}

Polymerizations were examined with the use of some supports and triethylaluminum in the absence of titanium tetrachloride. As shown in Table I, only an oily oligomer was obtained in these cases. Taking into account that the more acidic compound, $\mathrm{Ni}(\mathrm{OH}) \mathrm{Cl}$, gave a higher activity, it may be said that a cationic oligomeri-

Table I. Polymerization of propylene with the use of inorganic compounds as a support ${ }^{\mathrm{a}}$

\begin{tabular}{|c|c|c|c|c|c|}
\hline $\begin{array}{l}\text { Transition } \\
\text { metal halides }\end{array}$ & $\begin{array}{l}\text { Metal ion } \\
\text { in the support }\end{array}$ & Activity ${ }^{b}$ & I. I., $\%^{c}$ & $\bar{M}_{w}, \quad \times 10^{4}$ & $\begin{array}{l}\text { Surface area } \\
\text { of the support }\end{array}$ \\
\hline $\mathrm{TiCl}_{4}$ & $\mathrm{Ba}$ & 0.07 & 5 & 5.4 & 0.5 \\
\hline " & $\mathrm{Mg}$ & 4.1 & 54 & 10.6 & 8.4 \\
\hline " & $\mathrm{Mn}$ & 0.10 & 10 & 9.5 & - \\
\hline " & Co & 0.24 & 10 & 3.1 & 0.3 \\
\hline " & $\mathrm{Ni}$ & 0.11 & 16 & - & 0.2 \\
\hline " & $\mathrm{Cr}$ & 0.53 & 56 & - & - \\
\hline " & $\mathrm{Cd}$ & 0.05 & Oily & Very small & 0.3 \\
\hline " & $\mathrm{Sr}$ & 0.05 & $" \prime$ & "I & 1.5 \\
\hline " & $\mathrm{Fe}$ & 0.78 & 45 & - & - \\
\hline " & $\mathrm{Al}$ & 0.22 & 20 & - & - \\
\hline " & $\mathrm{Si}$ & 0.04 & Oily & Very small & 380 \\
\hline " & $\mathrm{Cu}$ & 0.02 & $"$ & " & - \\
\hline " & None & $7.1^{\mathrm{e}}$ & 53 & 5.5 & - \\
\hline None & $\mathrm{Ni}$ & 0.07 & Oily & Very small & 0.2 \\
\hline " & $\mathrm{Mg}$ & 0.01 & " & " & 8.4 \\
\hline
\end{tabular}

a $n$-heptane, $100 \mathrm{ml}$; catalyst, ca. $3 \mathrm{~g} ; \mathrm{Al}\left(\mathrm{C}_{2} \mathrm{H}_{5}\right)_{3}, 10 \mathrm{ml}$; at $50^{\circ} \mathrm{C}$.

b g-polymer/g-cat hr atm.

c Isotacticity of the polymer.

d $\mathrm{m}^{2} / \mathrm{g}$.

e Average rate during the initial $2 \mathrm{hr}$. 
zation should have occurred with these systems. Such a cationic oligomerization is considered to be strongly suppressed with supported catalysts owing to the reaction with titanium tetrachloride.

\section{Polymerizations with Supported Catalysts}

Polymerizations were carried out by using the supported catalysts with the conditions described in the experimental section. The results obtained are summerized in Table I. As for the polymerization activity (except for oligomerization), it is much higher with the use of some magnesium compounds. This may be attributed to their larger surface areas. The specific activity with these systems ( $c a .0 .5 \mathrm{~g}$-polymer $/ \mathrm{hr}$ atm $\mathrm{m}^{2}$-catalyst) stands comparison with that of $\alpha$-titanium trichloride.

On the other hand, it is of great interest that the tacticity of the polypropylene also depends remarkably on the support used. The importance of the crystal structure of a catalyst was already indicated by $\mathrm{Natta},{ }^{6}$ however, no detailed informations have been reported so far. As shown in Figure 1, a sharp peaked relationship with the maximum value near $0.70 \AA$ has been found between the tacticities of the polypropylenes produced and the ionic radius of the metals of the supports. The closer the ionic radius of the metal to that of $\mathrm{Ti}^{+4}$, the higher the tacticity of the polymer. These results strongly imply that the stereoregulation of a produced polymer is mainly attributed to

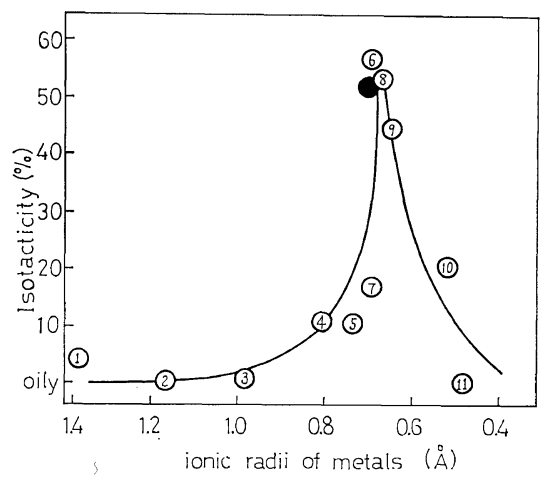

Figure 1. Dependence of the isotacticity on the ionic radii of the metals used as a support: $1, \mathrm{Ba}$; 2, $\mathrm{Sr} ; 3, \mathrm{Ca} ; 4, \mathrm{Mn} ; 5, \mathrm{Co} ; 6, \mathrm{Cr} ; 7, \mathrm{Ni} ; 8, \mathrm{Mg}$; 9, Fe; 10, Al; 11, Si; $\bigcirc$, Ti. the stereospecific coordination of propylene monomer onto the surface (or, more precisely, onto the active center) of the catalyst.

To estimate the propriety of this inference, it is of great help to measure both the heat and the entropy of propylene adsorption onto the individual active center. In practice, however, the polymerization reaction also takes place at the same time, so that such a measurement is impossible. Therefore, adsorption experiments were carried out by using only the supports for convenience. The results are shown in Table II.

Table II. Adsorption of propylene on various supports

\begin{tabular}{lccc}
\hline Support & $q^{a}$ & $\Delta S^{\mathrm{b}}$ & $\begin{array}{c}\text { Isotacticity, } \\
\%\end{array}$ \\
\hline $\mathrm{Mg}(\mathrm{OH})_{2}$ & $\sim 1$ & $\sim 0$ & 60 \\
$\mathrm{Mg}(\mathrm{OH}) \mathrm{Cl}$ & $\sim 1$ & $\sim 0$ & 54 \\
$\mathrm{Ni}(\mathrm{OH}) \mathrm{Cl}$ & Oligomerization took place & 16 \\
$\mathrm{Co}(\mathrm{OH}) \mathrm{Cl}$ & 5.9 & -16 & 10 \\
$\mathrm{Cd}(\mathrm{OH}) \mathrm{Cl}$ & $\sim 1$ & $\sim 0$ & Oily \\
$\mathrm{SiO}_{2}$ & 4.0 & -8.5 & Oily \\
\hline
\end{tabular}

a Heat of adsorption, $\mathrm{kcal} / \mathrm{mol}$.

b Entropy of adsorption, cal/deg mol.

The adsorption of propylene on these supports is very weak in general. Unfortunately, no reciprocity can be observed between the tacticities and the values of the heats and/or the entropies of propylene adsorption. Only the more acidic compound, $\mathrm{Ni}(\mathrm{OH}) \mathrm{Cl}$, was found to be active for an oligomerization in the absence of any activator. This result is consistent with the preceding discussion.

Effect of the Crystallinity of Supports. As mentioned before, some magnesium compounds such as $\mathrm{Mg}(\mathrm{OH}) \mathrm{Cl}$ and $\mathrm{Mg}(\mathrm{OH})_{2}$ were found to have excellent properties as supports for the stereospecific polymerization catalyst. It is still unknown, however, whether such excellent properties are based on the crystal structure or the other characteristics of the magnesium ion itself. To settle this problem, polymerizations were carried out by using several magnesium compounds as supports.

(1) Crystalline $\mathrm{Mg}(\mathrm{OH})_{2}$, whose crystal structure is very close to that of $\mathrm{Mg}(\mathrm{OH}) \mathrm{Cl}$, is well known ${ }^{7}$ to become amorphous on grinding. 
Thus, several $\mathrm{Mg}(\mathrm{OH})_{2}$ samples with different degrees of crystallinity were prepared by controlling the grinding time.

(2) The other magnesium compounds, whose crystal structures are considered to be very different from crystalline $\mathrm{Mg}(\mathrm{OH}) \mathrm{Cl}$ or $\mathrm{Mg}(\mathrm{OH})_{2}$, were prepared by adding $\mathrm{H}_{2} \mathrm{O}$ to a vigorously agitating etheral solution of $\mathrm{Mg}\left(\mathrm{C}_{2} \mathrm{H}_{5}\right)_{2}$ at $0^{\circ} \mathrm{C}$. The molar ratios of $\mathrm{Mg}\left(\mathrm{C}_{2} \mathrm{H}_{5}\right)_{2}$ to $\mathrm{H}_{2} \mathrm{O}$ were set at unity and two, respectively.

The polymerization results obtained from the use of these catalysts (Table III) show that the

Table III. Polymerization of propylene with the use of several magnesium compounds as a support ${ }^{a}$

\begin{tabular}{lc}
\hline Support & Isotacticity, $\%$ \\
\hline $\mathrm{Mg}(\mathrm{OH}) \mathrm{Cl}$ & 54 \\
$\mathrm{Mg}(\mathrm{OH})_{2}{ }^{\mathrm{b}}$ & 60 \\
$\mathrm{Mg}(\mathrm{OH})_{2}{ }^{\mathrm{c}}$ & 52 \\
$\mathrm{Mg}(\mathrm{OH})_{2}{ }^{\mathrm{d}}$ & 35 \\
$\mathrm{Mg}\left(\mathrm{C}_{2} \mathrm{H}_{5}\right)_{2}-\mathrm{H}_{2} \mathrm{O}(1 / 1)$ & 16 \\
$\mathrm{Mg}\left(\mathrm{C}_{2} \mathrm{H}_{5}\right)_{2}-\mathrm{H}_{2} \mathrm{O}(2 / 1)$ & Oily \\
$\mathrm{CrCl}_{3}$ & 65 \\
$\alpha-\mathrm{TiCl}_{3}$ & 70
\end{tabular}

a $n$-heptane, $100 \mathrm{~m} l$; catalyst, ca. $3 \mathrm{~g} ; \operatorname{Al}\left(\mathrm{C}_{2} \mathrm{H}_{5}\right)_{3}$, $10 \mathrm{ml}$; at $50^{\circ} \mathrm{C}$.

b Unground.

c Ground for $7 \mathrm{hr}$.

d Ground for $40 \mathrm{hr}$.

tacticities differ very much from one another. From these, it can be said that the stereoregulation of the produced polymer is mainly based on the crystal structure of the support (or the catalyst), not on the characteristic nature of the metal (magnesium).

From this point of view, the present authors have also reexamined the tacticity of a polymer produced by using chlomium chloride whose crystal structure is most similar to that of $\alpha$ titanium trichloride. Chromium chloride did not show any polymerization activity until it was treated for several hours at a high temperature under a nitrogen atmosphere. The tacticity obtained (Table III) is much higher than that reported by $\mathrm{Natta}^{8}\left(16.4 \%\right.$ isotactic at $70^{\circ} \mathrm{C}$, estimated by the extraction method) and very close to the tacticity with $\alpha$-titanium trichloride. This result also supports the above inference.
Polymerizations by Using Some Organic Polymers as a Support

Propylene polymerizations were also carried out by using some organic polymers as supports. Only an oily oligomer was obtained in these cases. These results are not in conflict with the previous inferences.

Kinetics of Propylene Polymerization. Kinetic studies of propylene polymerization were investigated with the use of the magnesium hydroxy chloride supported catalyst, whose catalytic activity was the best.

Time Dependence of the Polymerization Rate. In Figure 2 are shown typical results for the time dependence of the polymerization rate with various catalytic systems. It should be noted

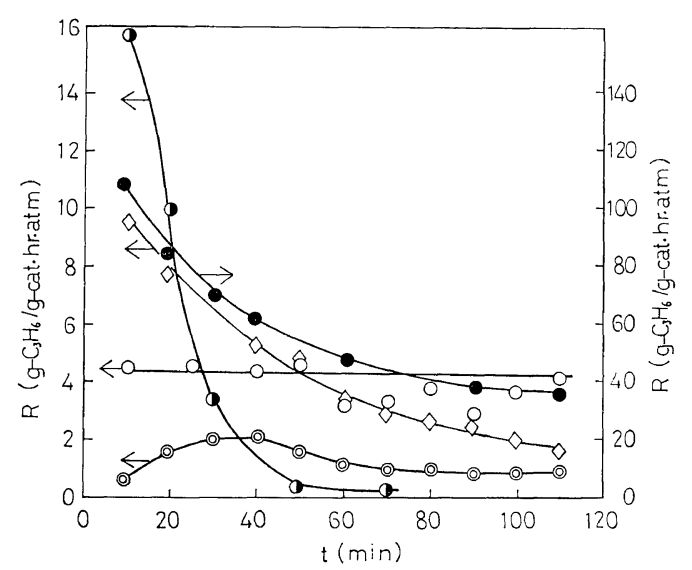

Figure 2. Time dependence of the polymerization rate with various catalysts at $50^{\circ} \mathrm{C}: n$-Heptane, $100 \mathrm{ml}$; each catalyst, ca. $1 \mathrm{~g} ; \mathrm{Al}_{(}\left(\mathrm{C}_{2} \mathrm{H}_{5}\right)_{3} ; 10 \mathrm{ml}$ : (). $\mathrm{TiCl}_{4}-\mathrm{Al}\left(\mathrm{C}_{2} \mathrm{H}_{5}\right)_{2} \mathrm{Cl} ; \bullet, \mathrm{TiCl}_{3}-\mathrm{Al}\left(\mathrm{C}_{2} \mathrm{H}_{5}\right)_{3} ; \diamond$, $\mathrm{TiCl}_{4}-\mathrm{Al}\left(\mathrm{C}_{2} \mathrm{H}_{5}\right)_{3} ; \bigcirc, \mathrm{TiCl}_{4} / \mathrm{Mg}(\mathrm{OH}) \mathrm{Cl}-\mathrm{Al}\left(\mathrm{C}_{2} \mathrm{H}_{5}\right)_{3} ;$ (อ), $\mathrm{TiCl}_{4} / \mathrm{Mg}(\mathrm{OH}) \mathrm{Cl}-\mathrm{Al}\left(\mathrm{C}_{2} \mathrm{H}_{5}\right)_{2} \mathrm{Cl}$.

here that the rates are all indicated per unit weight of the catalysts, so that those with the supported titanium tetrachloride are underestimated about one third. As well-known, the rate with activated titanium trichloride or carrier-free titanium tetrachloride decreases remarkably with the polymerization time, while that with the supported titanium tetrachloride remains constant over several hours during the course of polymerization. Similar results were obtained with the use of other supported 
catalysts. That is to say, the active centers become more stabilized by supporting titanium tetrachloride on magnesium chloride hydroxide support. This may be mainly attributed to the immobility of the active centers as the result of the fixation of them onto the surface of the support, i.e., such a deactivation as follows ${ }^{9}$ must be strongly suppressed with the supported catalysts.

$$
\mathrm{Ti}(\mathrm{IV})-\mathrm{R}+\mathrm{R}-\mathrm{Ti}(\mathrm{IV}) \rightarrow 2 \mathrm{Ti}(\mathrm{III})+\text { alkene + alkane }
$$

Besides this, the newly formed $\mathrm{Mg}-\mathrm{O}-\mathrm{Ti}$ bond may play some important role for suppressing the deactivation of the active centers, taking into account that a considerable deactivation occurs as shown in Figure 2 even with solid titanium trichloride, where the active centers are also considered to be strongly fixed on the surface. Similar results were also obtained with the use of vanadium tetrachloride as a transition metal halide.

\section{Influence of the Concentration of a Transition Metal Halide}

To investigate the influence of the amount of supported transition metal halide on the polymerization rate, polymerizations were carried out at $50^{\circ} \mathrm{C}$ by using some magnesium chloride hydroxide-supported catalysts prepared with various concentrations of titanium tetrachloride. The polymerization rate with every case does

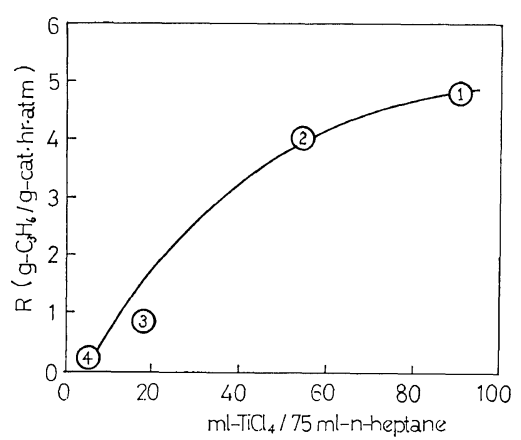

Figure 3. Polymerization rate at $50^{\circ} \mathrm{C}$ by using the supported $\mathrm{TiCl}_{4}$ catalysts with various amounts of supported $\mathrm{TiCl}_{4}$. (Abscissa indicates the concentration of $\mathrm{TiCl}_{4}$ in the preparation of the supported catalyst). $n$-Heptane, $100 \mathrm{ml}$; catalyst, $c a$. $1 \mathrm{~g} ; \mathrm{Al}\left(\mathrm{C}_{2} \mathrm{H}_{5}\right)_{3} ; 10 \mathrm{ml}$. not change with the polymerization time. Figure 3 shows the stationary polymerization rates as a function of the concentration of titanium tetrachloride. As is well-known, the polymerization rate depends on the concentration of the activator, triethyl aluminum. However, in the present case it is used in excess, so that it's effect on the polymerization rate can be ignored.

As can be seen in Figure 3, the polymerization rate increases with increasing concentration of titanium tetrachloride and reaches a saturated value. This result may be explained by assuming that the polymerization rate is proportional to the surface concentration of titanium tetrachloride.

\section{Temperature Dependence of the Polymerization Rate}

The temperature dependence of the polymerization rate was investigated with various catalytic systems, the results of this study are shown in Figure 4 . Since the polymerization rate decreases remarkably with the polymerization time on carrier-free titanium tetrachloride (Figure 2), in this case the average rates during the initial $2 \mathrm{hr}$ are shown in place of the stationary rates. On the other hand, the rate with the supported catalysts does not change

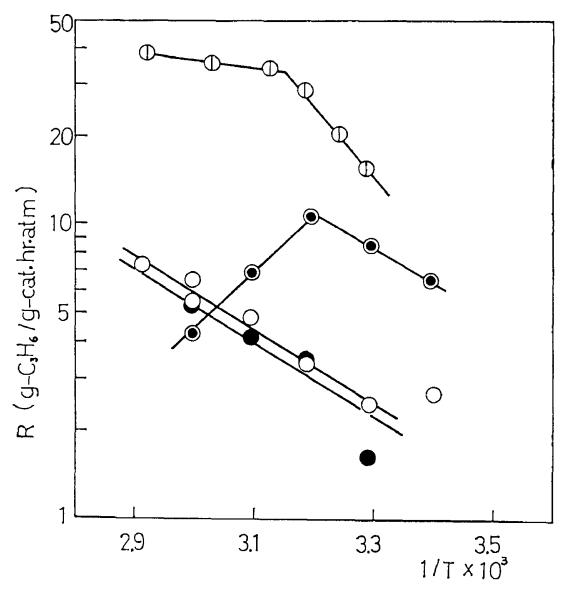

Figure 4. Temperature dependence of the polymerization rate with various catalysts: (1), $\mathrm{TiCl}_{3}-$ $\mathrm{Al}\left(\mathrm{C}_{2} \mathrm{H}_{5}\right)_{3} ; \odot, \mathrm{TiCl}_{4}-\mathrm{Al}\left(\mathrm{C}_{2} \mathrm{H}_{5}\right)_{3} ; \bigcirc, \mathrm{TiCl}_{4} / \mathrm{Mg}(\mathrm{OH})-$ $\mathrm{Cl}-\mathrm{Al}\left(\mathrm{C}_{2} \mathrm{H}_{5}\right)_{3}(1) ; 0, \mathrm{TiCl}_{4} / \mathrm{Mg}(\mathrm{OH}) \mathrm{Cl}-\mathrm{Al}\left(\mathrm{C}_{2} \mathrm{H}_{5}\right)_{3}$ (2) (The numbers 1 and 2 correspond to those in Figure 3). $n$-Heptane, $100 \mathrm{ml}$; catalyst, ca. $1 \mathrm{~g}$; $\mathrm{Al}\left(\mathrm{C}_{2} \mathrm{H}_{5}\right)_{3} ; 10 \mathrm{ml}$. 
with the polymerization time even at $70^{\circ} \mathrm{C}$. Similar results were also obtained with the use of the other supported catalysts.

As is well-known, the apparent activation energy of the polymerization with carrier-free titanium tetrachloride decreases with increasing the polymerization temperature, perhaps, owing to the deactivation of the active centers. On the other hand, the activation energy with the supported catalysts does not decrease at all. This strongly indicates that the active centers become much stabilized with the use of a magnesium chloride hydroxide support. The apparent activation energy with the supported catalysts is equal to that for the case of carrierfree titanium titrachloride below about $40^{\circ} \mathrm{C}$, and lower than the activation energy in the case of titanium trichloride by about $4.5 \mathrm{kcal} / \mathrm{mol}$. This may support the above assumption that the valence state of titanium in the supported catalysts remains four.

\section{CONCLUSIONS}

From the above results, the present authors have come to the following conclusions:

(1) These supports strongly stabilize the active centers, and

(2) The stereoregulation of the produced polymer is mainly based on the crystal structure of the support (or the catalyst).

\section{REFERENCES}

1. For example, Belg. Pat., 705,220 (Solvey).

2. T. Keii, M. Taira, and T. Takagi, Can. J. Chem., 41, 206 (1963).

3. Kinsinger, Paper presented at the 132nd Meeting, American Chemical Society, New York, N.Y., Sept. 1957.

4. J. P. Luongo, J. Polym. Sci., 3, 302 (1960).

5. J. Murray, M. J. Sharp, and J. A. Hockey, J. Catalysis, 18, 52 (1970).

6. G. Natta, J. Polym. Sci., 84, 21 (1959).

7. Y. Arai, N. Yasue, and H. Miyake, Nippon Kagaku Zassi (J. Chem. Soc. Japan, Pure Chem. Sect.) 3, 547 (1972).

8. G. Natta, A. Zambelli, I. Pasquon, and G. M. Giongo, Chim. Ind. (Milan), 48, 1307 (1966).

9. G. Henrici-Olive and S. Olive, J. Organometal. Chem., 16, 339 (1969). 